\title{
ASPECTOS MECANÍSTICOS DA BIOATIVIDADE E TOXICIDADE DE NITROCOMPOSTOS
}

Fávero Reisdorfer Paula

Departamento de Farmácia, Setor de Ciências da Saúde, Universidade Estadual do Centro-Oeste do Paraná, Guarapuava - PR, Brasil

Silvia Helena Pires Serrano

Departamento de Química Fundamental, Instituto de Química, Universidade de São Paulo, 05508-900 São Paulo - SP, Brasil Leoberto Costa Tavares*

Departamento de Tecnologia Bioquímico-Farmacêutica, Faculdade de Ciências Farmacêuticas, Universidade de São Paulo, 05508-900 São Paulo - SP, Brasil

Recebido em 14/3/08; aceito em 23/10/08; publicado na web em 6/3/09

\begin{abstract}
ASPECTS OF BIOACTIVITY AND TOXICITY OF NITROCOMPOUNDS. Nitrocompounds are bioactive molecules used as antibacterial, antiparasitic and antitumoral agents. In the past of years, these molecules have been broadly studied in several fields, such as medicinal chemistry, organic chemistry, biochemical, toxicology and electrochemistry. The nitrocompounds mode of action involves the biotransformation of the nitro group, releasing intermediates in the redox process. Some of those intermediates attack enzymes, membranes and DNA, providing the basis for their biological activity and adverse effects. In this report, some aspects regarding the biological activity, mechanism of action and toxicity of nitrocompounds are explored, purposing the research of new bioactive derivatives having low toxicity.
\end{abstract}

Keywords: nitrocompounds; toxic radicals; biological activity.

\section{INTRODUÇÃO}

O arsenal terapêutico atualmente disponível permite o tratamento da maioria das doenças. ${ }^{1}$ No entanto, a eficácia da quimioterapia depende de fatores como a incidência de resistência microbiana, efeitos colaterais e tóxicos, baixa eficácia e seletividade. Adicionalmente, a ausência de compostos eficazes frente a doenças órfãs, como algumas doenças infecto-contagiosas e alguns tipos de câncer evidenciam as deficiências da terapêutica atual. ${ }^{1-5}$ Estes fatos demonstram a necessidade premente de desenvolvimento de novos agentes bioativos, com eficácia comprovada, para o tratamento dessas enfermidades e que possuam toxicidade e efeitos colaterais compatíveis com a condição de fármaco. Neste sentido, alguns nitrocompostos, candidatos potenciais a agentes terapêuticos, destacam-se como antibacterianos, antiparasitários e até como antineoplásicos, o que ressalta a importância desta classe de compostos.

Maior atenção foi dada aos nitrocompostos a partir da década de 40 com sua introdução e emprego em terapêutica, período em que milhares de compostos desta classe foram sintetizados e testados frente a diversas doenças. ${ }^{6-8}$ Nas décadas de 50 e 60, a observação da incidência de efeitos tóxicos desses compostos aliados ao surgimento de novos agentes antibacterianos resultou em queda, em alguns países, do emprego de nitrocompostos em farmacoterapia. ${ }^{9}$ Apesar disso, o uso desses compostos nunca foi descontinuado, visto que alguns desses fármacos continuaram sendo utilizados no combate a alguns tipos de infecções em humanos e, mais amplamente, em medicina veterinária. ${ }^{6,7}$

A atividade biológica desta classe de compostos é dependente da presença do grupo nitro ligado à molécula e resulta, basicamente, de mudanças na estabilidade do mesmo, intermediada por interações entre o nitrocomposto e o seu alvo na biofase. Em nível molecular estas mudanças ocorrem devido à facilidade de redução do grupo nitro, característica resultante de seu caráter fortemente aceptor de

*e-mail: leoberto@usp.br elétrons, bem como pelo efeito de ressonância entre o nitrogênio e os dois átomos de oxigênio de sua estrutura. ${ }^{10,11}$ Neste sentido e como exemplo da importância das propriedades físico-químicas do grupo nitro para o desencadeamento da atividade biológica citam-se, entre muitos, alguns nitrocompostos que são amplamente utilizados como fármacos, como o cloranfenicol, um agente antimicrobiano, a ranitidina, um inibidor da secreção gástrica, e a flutamina, um antiandrogênio não esteroidal. ${ }^{12} \mathrm{O}$ efeito biológico, em alguns casos, pode também resultar da interação desses compostos com receptores específicos da biofase, sem que a redução catalítica do grupo nitro seja o elemento essencial da bioatividade do composto. A maioria dos compostos nitrados, no entanto, apresenta o mecanismo de biorredução enzimática, o que resulta na formação de radicais livres com toxicidade preferencial para células bacterianas e parasitárias.

\section{ATIVIDADE BIOLÓGICA}

Os nitrocompostos já foram empregados em várias classes terapêuticas ${ }^{6,8,11,13}$ e atualmente possuem diversas aplicações clínicas, entre as quais citam-se usos como antianginosos (dinitrato de isossorbida, nitroglicerina), anti-hipertensivos (nifedipina, nitredipina e nisoldipina), anticoagulante (acenocumarol), sedativo hipnótico (nitrazepan), analgésico narcótico (clonitiazina), anti-inflamatório (nimesulida), anti-histamínico $\mathrm{H}-2$ (ranitidina), antibacterianos (cloranfenicol, metronidazol, nitrofural, nifuroxazida), antineoplásicos (nitacrina, 1-(1,5-dicloropentano-3-il)-4-nitrobenzeno) e antiparasitários (metronidazol, tinidazol, secnidazol, benzinidazol e nifurtimox). ${ }^{1,6,9,14-16}$ Entre as diversas classes de nitrocompostos que apresentam interesse biológico, algumas de maior relevância estão representadas, na Figura 1, por suas estruturas químicas fundamentais. A maioria dos nitrocompostos com ação antineoplásica, antiparasitária e antibacteriana apresentam o processo de biorredução enzimática do grupo nitro como provável mecanismo de ação, ${ }^{14,16,17}$ o que coloca este requisito como sendo imprescindível para o desempenho da 
atividade biológica destes compostos. Apresentam-se, na Figura 2, os possíveis processos de redução enzimática do grupo nitro in vivo e na Tabela 1 citam-se algumas referências que demonstram o emprego potencial destes compostos como candidatos a fármacos. É importante destacar que o melhor desempenho da atividade biológica pode ocorrer com a introdução de novos nitrocompostos, baseados em estruturas já conhecidas e com bioatividade comprovada, resultantes de modificações moleculares planejadas com base na influência de propriedades físico-químicas que influenciam a atividade desta classe de compostos. Neste contexto, ressalta-se que a maioria dos trabalhos citados envolve o emprego de modificação estrutural dos nitrocompostos utilizando a ferramenta de bioisosterismo, amplamente empregada no planejamento e desenvolvimento de diversas classes terapêuticas. ${ }^{12}$
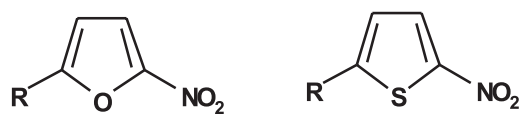<smiles>[R]c1ccc([N+](=O)[O-])cc1</smiles>

Derivados Nitrobenzênicos

\section{Derivados Nitrotiofênicos}<smiles>[R]C1=NCN([R])C1[N+](=O)[O-]</smiles>

Derivados

Nitroimidazólicos
Figura 1. Subestruturas químicas fundamentais de nitrocompostos empregados em terapêtica

\section{MECANISMO DE AÇÃO}

Ao estudar os nitrocompostos, observa-se que o mecanismo de ação, em nível molecular, ainda não está totalmente estabelecido, uma vez que pode variar de acordo com diferenças estruturais dos compostos. A passagem transmembrana destas moléculas ocorre por difusão passiva e aumenta à medida que os radicais livres, provenientes do processo de biorredução, desestabilizam a membrana celular. Assim, devido ao aumento da concentração intracelular de nitrocompostos, maior quantidade de radicais livres é gerada e, conseqüentemente, maior é o dano causado pelo estresse oxidativo. ${ }^{14}$ De acordo com dados da literatura é consenso que o mecanismo de ação desta classe de compostos está ligado ao processo de redução in vivo do grupo nitro e à subseqüiente interação dos produtos formados, a partir desta reação, com biomoléculas essenciais de bactérias, fungos e parasitas. ${ }^{16,17,52,53}$

A ativação biológica através do processo de biorredução de nitrocompostos apresenta-se como alvo para o aperfeiçoamento da atividade biológica desta classe de compostos. Assim, Rozenski e colaboradores, em 1995, conseguiram relacionar a ação antibacteriana com o potencial de redução de alguns nitrocompostos,
Tabela 1. Classes de nitrocompostos e respectivo emprego na terapêutica

\begin{tabular}{|c|c|c|}
\hline Classe & Agente etiológico & Ref. \\
\hline \multirow{4}{*}{ Nitrotiofênicos } & $\begin{array}{c}\text { Entamoeba histolitica, Leishmania } \\
\text { sp, Trichomonas sp, Trypanosoma } \\
\text { cruzi }{ }^{+}\end{array}$ & 18 \\
\hline & $\begin{array}{c}\text { Entamoeba histolítica, Leishmania sp, } \\
\text { Trichomonas sp, Trypanosoma cruzi, } \\
\text { Plasmodium falciparum }{ }^{+}\end{array}$ & 19,20 \\
\hline & Staphylococus aureus* & 21 \\
\hline & Micobacterium* & 22 \\
\hline \multirow{3}{*}{$\begin{array}{l}\text { Nitrotiofênicos/ } \\
\text { Nitrofurânicos }\end{array}$} & Leishmania major ${ }^{+}$ & 23 \\
\hline & Trypanosoma brucei $i^{+}$ & 24 \\
\hline & Trypanosoma cruzi $i^{+}$ & $25-28$ \\
\hline \multirow{7}{*}{ Nitrofurânicos } & Trypanosoma cruzi $i^{+}$ & $27-36$ \\
\hline & $\begin{array}{c}\text { Staphylococus aureus, Camphy- } \\
\text { lobacter crescentus* }\end{array}$ & 37 \\
\hline & Staphylococus aureus* & $38-40$ \\
\hline & Escherichia coli* & 40,41 \\
\hline & Micobacterium tuberculosis* & 42 \\
\hline & Entamoeba histolitica ${ }^{+}$ & 43 \\
\hline & Candida albicans ${ }^{\mp}$ & 40 \\
\hline $\begin{array}{l}\text { Nitrofurânicos/ } \\
\text { Nitroimidazóis }\end{array}$ & $\begin{array}{l}\text { Clostridium perfringes, } \\
\text { Bacterioides } s p^{*}\end{array}$ & 44 \\
\hline \multirow{4}{*}{ Nitroimidazóis } & Micobacterium tuberculosis* & 45,46 \\
\hline & Trypanosoma cruzi $i^{+}$ & $27,47-49$ \\
\hline & Giardia muris $^{\mp}$ & 50 \\
\hline & Candida albicans $^{\mp}$ & 51 \\
\hline
\end{tabular}

Nitrocompostos com atividade antiparasitária ${ }^{+}$, antibacteriana* e antifungica ${ }^{\mp}$.

comprovando que esta bioatividade é decorrente da redução do grupo nitro. ${ }^{44}$ Neste contexto, podem ser observados estudos sobre o mecanismo de biorredução do grupo nitro e a determinação do potencial de redução por meio de técnicas eletroquímicas, sendo possível, deste modo, conhecer os intermediários formados e estimar, para cada um destes, a possibilidade de atividade biológica. ${ }^{54}$ A redução completa destes compostos, Figura 3, envolve 6 elétrons até o derivado amino, embora o intermediário hidroxilamina, envolvendo 4 elétrons, seja o produto final da biorredução de alguns nitrocompostos.

Em meio anaeróbio, o nitro radical aniônico e a hidroxilamina formados são os principais intermediários ou metabólitos do processo de redução enzimática do grupo nitro até amino. O radical $\mathrm{Ar}-\mathrm{NO}_{2}{ }_{2}^{--}$e o derivado hidroxilamina (Ar- $\mathrm{NHOH})$ podem interagir com o DNA celular, o que resulta nos efeitos biológicos observados. Todavia, existem suspeitas de que outros intermediários também apresentem atividade biológica, entre as quais, a toxicidade ao DNA supostamente causada pelo radical $\mathrm{Ar}_{-} \mathrm{NO}_{2} \mathrm{H}^{++}$e a inativação enzimática desempenhada pelo

$$
\mathrm{Ar}-\mathrm{NO}_{2} \stackrel{1 \mathrm{e}^{-}}{\rightleftharpoons} \mathrm{Ar}-\mathrm{NO}_{2} \stackrel{--1 \mathrm{e}^{-}}{\longrightarrow} \mathrm{Ar}-\mathrm{NO} \stackrel{2 \mathrm{e}^{-}}{\rightleftharpoons} \mathrm{Ar}-\mathrm{NHOH} \stackrel{2 \mathrm{e}^{-}}{\longrightarrow} \mathrm{Ar}-\mathrm{NH}_{2}
$$




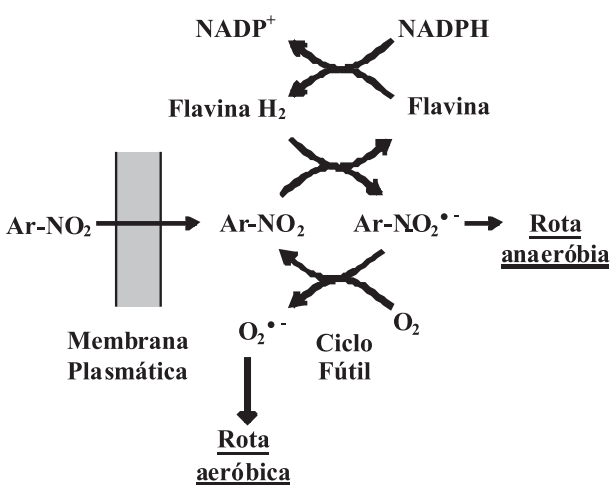

Rota Anaeróbia

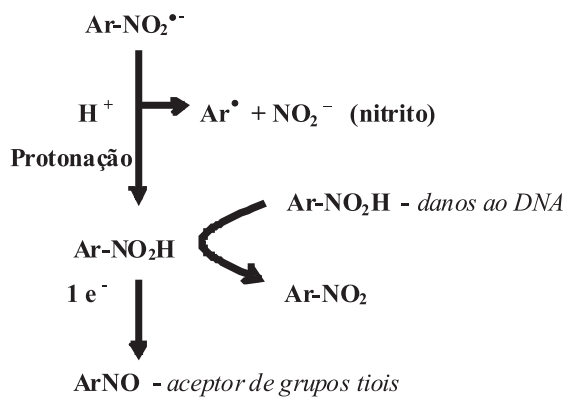

(derivado nitroso)

$2 \mathbf{H}^{+}+2 \mathrm{e}^{-}$

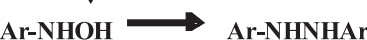

(hidroxilamina) (azoxi composto)

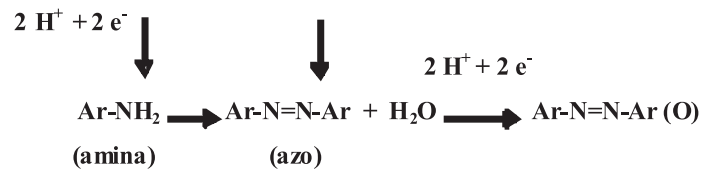

$\underline{\text { Rota aeróbia }}$

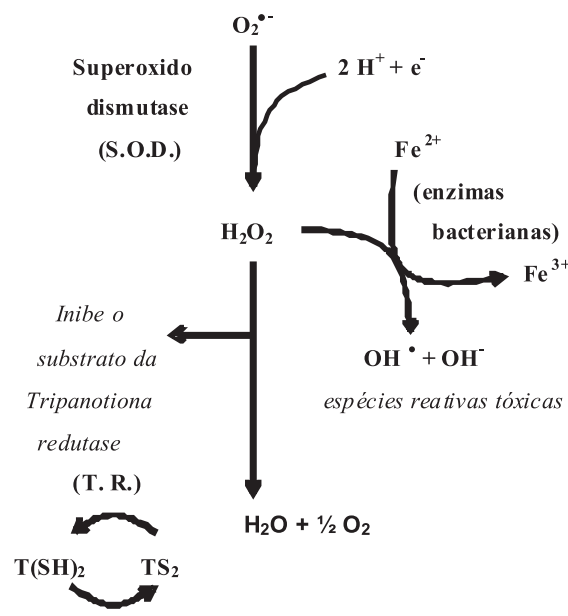

Figura 3. Provável mecanismo biorredutivo de nitrocompostos aromáticos $^{14,16,55,74}$ derivado nitroso (Ar-NO), agindo como aceptor de grupos tióis de enzimas detoxificantes. Em meio aeróbio, o nitro radical aniônico gerado no processo de redução enzimática interage com o oxigênio presente no meio, em uma etapa metabólica denominada ciclo fútil, ${ }^{16}$ formando o radical $\mathrm{O}_{2}{ }^{-}$. Este radical, por sua vez, sofre ação de enzimas como a superóxido dismutase, S.O.D., formando peróxido de hidrogênio - $\mathrm{H}_{2} \mathrm{O}_{2}$ - que pode desestruturar membranas biológicas e também reagir com enzimas ferrodoxinas, liberando espécies reativas $\left(\mathrm{OH}^{*}\right)$ que são tóxicas para as células bacterianas e parasitárias..$^{14,16,17,53}$ Assim, de acordo com a Figura 3, verifica-se que o processo de redução depende da estrutura do nitrocomposto e do meio onde ocorre. Neste processo, existem evidências que a recepção de 1 elétron a partir do primeiro passo de redução do grupo nitro, demonstrado pelo par Ar-

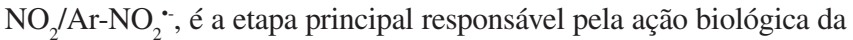
maioria dos nitrocompostos. ${ }^{14,16,17}$

Com relação à atividade antibacteriana, do mesmo modo como descrito para alguns parasitas, alguns compostos nitro-heterocíclicos são metabolizados por redutases ligadas à ferrodoxina (fotobactérias) e pelo complexo piruvato (flavoproteínas $\mathrm{NAD}(\mathrm{P}) \mathrm{H}$ e ferrodoxinas) de alguns microrganismos com comportamento aeróbio ou anaeróbio. ${ }^{14,56} \mathrm{~A}$ redução do grupo nitro em parasitas como o Trypanosoma cruzi, no entanto, ocorre por meio de flavoenzimas, enquanto que a ação terapêutica corresponde à produção de nitro radicais aniônicos e peróxidos que podem inibir algumas enzimas que detoxificam os radicais livres, como a tripanotiona redutase, ou mesmo interagir com o substrato desta enzima, tornando o parasita suscetível à ação tóxica destes radicais. ${ }^{16,54} \mathrm{~A}$ capacidade de redução de certos sistemas enzimáticos em microrganismos aeróbios alcança valores de até no máximo - 0,35 V, diferentemente dos anaeróbios que conseguem reduzir nitrocompostos em valores próximos a - 0,5 V. Esta diferença de potencial de redução entre os diversos nitrocompostos resulta em base importante para o entendimento da toxicidade seletiva para os microrganismos. Adicionalmente, a ativação redutiva em anaeróbios somente é possível em intervalo limitado de potencial de certos sistemas enzimáticos, o que comprova a seletividade de alguns compostos. ${ }^{14,58}$ Os valores dos potenciais de redução de alguns nitrocompostos podem ser observados na Figura 4.

A facilidade de redução de alguns nitrofuranos, Figura 4, demonstra que o grupo nitro é reduzido por microrganismos aeróbios e anaeróbios, justificando a perda da seletividade destes compostos. Neste contexto, a nitrofurantoína, por exemplo, apresenta nitrorredução eficiente (cerca de $-0,3 \mathrm{~V}$ ) em meio contendo alta concentração das enzimas do citocromo P-450, NADPH dependente, de mamíferos comprovando, assim, a falta de seletividade de alguns nitrocompostos frente a células bacterianas e humanas. ${ }^{56} \mathrm{~A}$ formação dos radicais

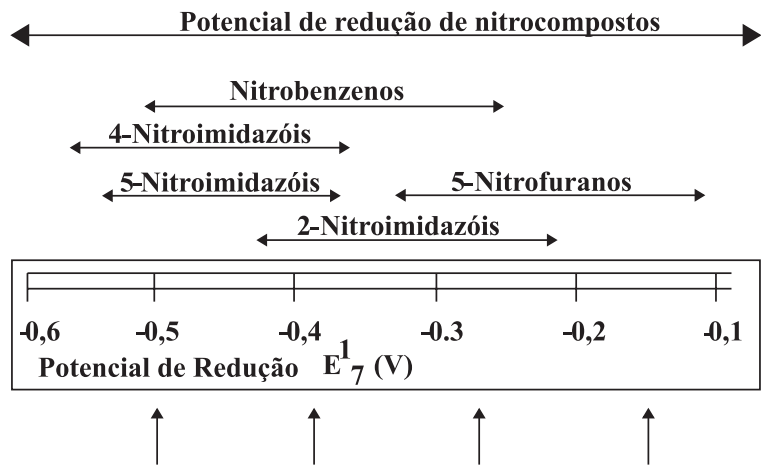

Metronidazol Misonidazol Nitrofurantoína Oxigênio

Figura 4. Intervalo de variação do potencial de redução dos nitrocompostos e do oxigênio. Adaptado da ref. 58 
livres provenientes do processo de biorredução do grupo nitro pode resultar em peroxidação de membranas biológicas e proteínas, inibição de enzimas e danos ao DNA. ${ }^{14}$

Um dos processos envolvidos na biorredução do grupo nitro em anaeróbios e algumas vezes, em aeróbios, é a interrupção do fluxo normal de elétrons da cadeia respiratória, o que interfere na degradação de carboidratos, na transposição de prótons $\mathrm{H}^{+}$e na produção de energia. Este mecanismo, Figura 5, inicialmente descrito para os nitrofuranos, poderia ocorrer por meio da inibição de algumas enzimas, pertencentes ao ciclo do ácido cítrico, envolvidas na formação de acetil coenzima A, CoA-SH, a partir do ácido pirúvico, e no subseqüente processo de respiração celular. ${ }^{6,11,14,52,59}$ As enzimas do complexo piruvato de microrganismos são responsáveis pela redução de alguns nitrocompostos promovendo a formação de radicais livres $\left(\mathrm{Ar}_{-} \mathrm{NO}_{2}{ }^{-}\right.$e $\left.\mathrm{OH}^{*}\right)$ e a interrupção do fluxo fisiológico de elétrons. ${ }^{27} \mathrm{O}$ evento letal, porém, não é a inibição da respiração e sim a formação dos radicais tóxicos provenientes do estresse oxidativo. ${ }^{14,27}$

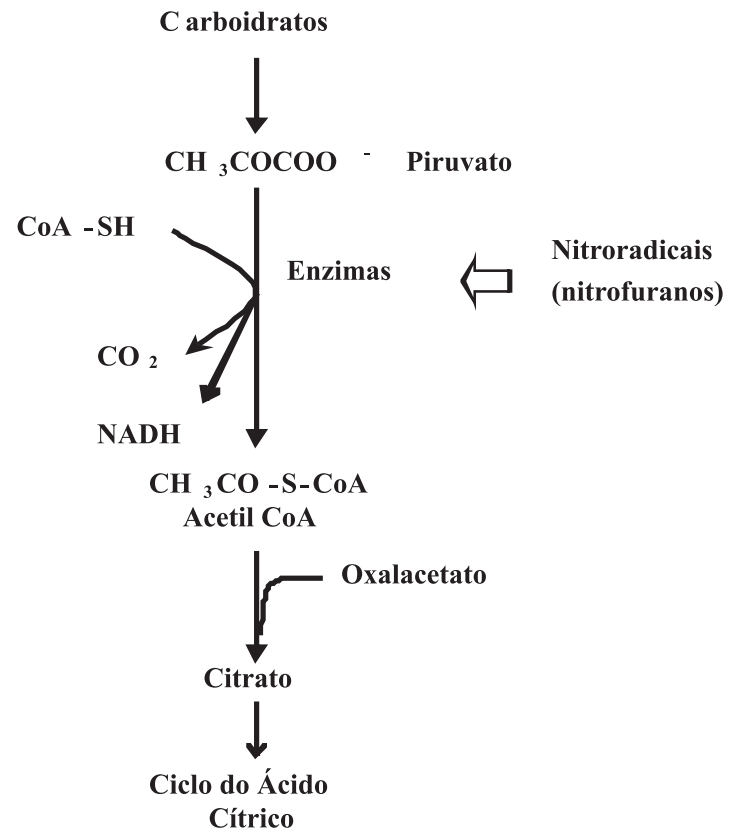

Figura 5. Ação de radicais livres provenientes do processo de redução de nitrocompostos em enzimas do ciclo do ácido cítrico. Adaptado da ref. 11

Outro mecanismo de ação proposto para os nitrocompostos e observado por Maya e colaboradore s $^{27,60}$ caracteriza-se pela ligação de intermediários do processo de redução a grupos tióis de enzimas essenciais de alguns parasitas e bactérias, o que resulta em decréscimo e inativação destas enzimas. Estes autores sugeriram que a suscetibilidade de parasitas, neste caso o Trypanosoma cruzi, é dependente da concentração de grupos tióis presentes no seu organismo. MacOsker e colaboradores, em 1994, estudando o efeito da nitrofurantoína em cepas de Escherichia coli, sugeriram que intermediários da nitrorredução atacam enzimas tióis microssômicas não específicas com conseqüente inibição da síntese protéica e do subseqüente crescimento da população destas bactérias. ${ }^{61}$ Viodé e colaboradores, em 1999, em estudo envolvendo o megazol, um nitrocomposto que apresenta atividade frente a diferentes cepas de Trypanosoma cruzi, propuseram dois mecanismos de ação para este composto, sendo o primeiro descrito como a redução enzimática do nitrocomposto com subseqüente formação de nitrorradicais e o segundo, como a possibilidade de inibição direta da fumarato reductase, uma enzima tiólica essencial ao parasita. ${ }^{16}$ Este último mecanismo, entretanto, não é o evento letal para a célula, onde, primeiramente, a concentração enzimática de grupos tióis diminui com conseqüiente redução da atividade das enzimas detoxificantes e aumento na produção de radicais livres, resultando em dano celular a parasitas e bactérias. ${ }^{60}$

Em relação aos diversos mecanismos de ação descritos para os nitrocompostos, existem evidências de que o DNA, Figura 3, é o alvo dos intermediários de redução formados a partir destes compostos. Para provar esta hipótese, Edwards, em 1986, realizou experimento com nitroimidazóis e partes de DNA adicionadas em três fases diferentes. A saber: antes, durante e depois do término do processo de biorredução do grupo nitro. ${ }^{52}$ De acordo com os resultados obtidos, verificou-se a falta de atividade dos compostos quando estes foram adicionados depois da redução, sugerindo, assim, que o dano ao DNA seria causado por nitrorradicais formados na biorredução do nitrocomposto. $\mathrm{O}$ autor sugeriu, ainda, que os radicais livres e os intermediários formados no processo de redução dos compostos da classe dos 2-nitroimidazóis e 5-nitroimidazóis induzem a liberação de fosfato de timidina, o que promove a desestabilização e ruptura da dupla hélice de DNA e sua subseqüente destruição. A lesão ao DNA depende de fatores como o pH do meio onde ocorre a reação de redução e da composição das bases do DNA e aumenta com a concentração de bases adenina e timina. ${ }^{16}$ Neste processo, a formação e a detecção de intermediários decresce em presença de resíduos de timina, supondo-se, portanto, que este mecanismo promova maior atividade frente a células que contêm maior concentração do par Adenina-Timina (A-T) na cadeia de DNA. A interação do DNA com os intermediários de redução, mais precisamente o $\mathrm{Ar}-\mathrm{NO}_{2}{ }^{-}$, depende da estabilidade deste radical e de sua reatividade frente ao DNA. Neste contexto, os radicais que apresentam maior meia-vida e, portanto, cinética de decomposição mais lenta produzem lesão no DNA maior em comparação àqueles que apresentam reações de decomposição mais rápidas, indicando diferentes reatividades entre os vários nitrocompostos. ${ }^{14,55}$ Além do par de bases A-T existem outros possíveis alvos no DNA, como a guanina, presente no par de bases Guanina-Citosina (G-C), que pode sofrer a ação de intermediários resultantes da redução de compostos 5-nitroimidazóis, causando a ruptura da dupla hélice de DNA. ${ }^{62}$

\section{ATIVIDADE ANTINEOPLÁSICA}

Os nitrocompostos também têm despertado interesse na terapia antineoplásica, principalmente no tratamento de tumores sólidos contendo áreas com hipóxia, resultantes de vascularização insuficiente destes tecidos. ${ }^{6,14,63-67} \mathrm{O}$ ambiente de baixa concentração de oxigênio intracelular permite a biorredução dos nitrocompostos e subseqüente formação de radicais livres em potenciais de redução menores que o observado para células normais; este fator provém base para a atividade citotóxica seletiva de células em hipóxia, contribuindo assim para a ação de fármacos antineoplásicos e dando margem para o planejamento de novos compostos mais específicos em relação a esta função. ${ }^{14,67}$ Alguns compostos desta classe possuem capacidade para sensibilizar células com hipóxia para a radiação ionizante. Entre estes, os 5-nitroimidazóis e os 2-nitroimidazóis podem ser utilizados como radiossensibilizantes, ${ }^{65,68}$ uma vez que o grupo nitro atua como aceptor de elétrons dos radicais formados pela radiação ionizante junto ao DNA, formando radicais que ocasionam dano e quebra da dupla hélice..$^{5,14,69}$ Neste mecanismo, o evento químico que determina o efeito da radiossensibilização é o potencial de redução do grupo nitro. Outro fator importante a ser observado é a afinidade eletrônica do grupo nitro, que quanto maior for maior será a sua capacidade 
radiossensibilizante. ${ }^{52}$ Ressalta-se que este efeito é o oposto daquele observado para a atividade antibacteriana. Este campo de aplicação carece ainda de estudos mais aprofundados e apresenta grande perspectiva de crescimento no que diz respeito ao desenvolvimento de futuros compostos radiossensibilizantes.

Além dos mecanismos já descritos, outro modo de ação dos nitrocompostos que opera por meio do emprego da redução do grupo nitro é a alquilação biorredutiva. Este mecanismo é exemplificado na Figura 6 com o 1-(1,5-dicloropentano-3-il)-4-nitrobenzeno, onde o agente alquilante sofre ativação endógena através da redução do grupo nitro até hidroxila ou amina..$^{70,71}$ Neste caso, o grupo nitro atua como aceptor de elétrons o que dificulta, por meio de interação eletrônica da molécula, a retirada dos átomos de cloro da mesma, característica que é perdida após a redução e a formação de amina. Desse modo, o grupo nitro tem a função de ativar o agente alquilante em sítios específicos que possibilitam a sua biorredução próximo ao DNA da célula neoplásica. ${ }^{70,71}$

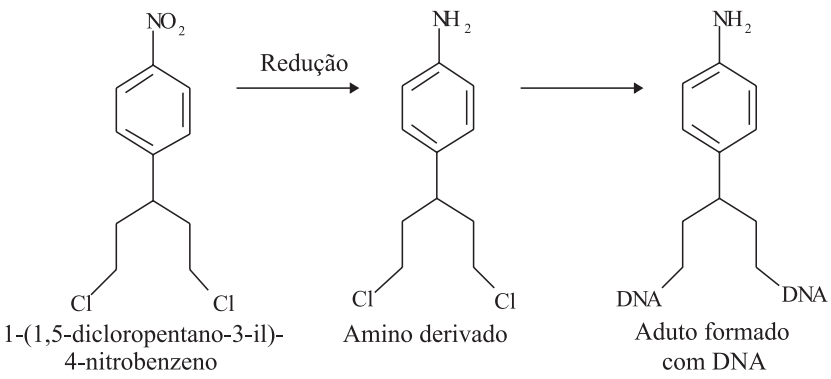

Figura 6. Ativação de 1-(1,5-dicloropentano-3-il)-4-nitrobenzeno por mecanismo de biorredução

\section{TOXICIDADE}

Os nitrocompostos têm sido alvo de inúmeras discussões visando o esclarecimento de sua toxicidade. Os efeitos tóxicos mais comuns apresentados por nitrocompostos, como metronidazol, nitrofural, benznidazol e nifurtimox, são estomatite, anorexia, diarréia e náuseas ${ }^{1,72}$ e algumas vezes dermatites, polineurites e discrasias sanguíneas, quadros que podem ser agravados em decorrência de hipersensibilidade e da dose empregada. ${ }^{1,9,11,15,72}$ Alguns nitrocompostos necessitam de cuidados especiais em relação ao seu uso terapêutico, Bartel e colaboradores avaliaram que o nifurtimox pode causar alterações estruturais no tecido cardíaco de ratos. Os autores sugerem que este fármaco deve ser utilizado com mais atenção em pacientes com pré-disposição a doenças cardíacas. ${ }^{73}$ Destacam-se também os efeitos tóxicos causados pelo uso do cloranfenicol, um nitrocomposto amplamente utilizado como antibacteriano, que causa anemia aplásica e diversas outras discrasias sanguíneas como efeitos colaterais, na dependência da dose utilizada e tempo de exposição. Estudos referentes à substituição isostérica do grupo nitro deste fármaco pelo grupo metilsulfonil resultaram na obtenção do tianfenicol, que demonstra ausência dos efeitos colaterais correspondentes à anemia aplásica. ${ }^{74}$ Em outro caso, o megazol, agente tripanocida, teve seu desenvolvimento descontinuado devido à toxicidade e mutagenicidade demonstrada em ensaios realizados in vivo..$^{75-77}$ Ademais, a presença do grupo nitro ligado a anéis aromáticos pode ser relacionada à incidência de efeitos tóxicos causados pela redução in vivo dos compostos nitroaromáticos. ${ }^{14}$

A possibilidade de a atividade biológica ser dependente da ligação dos intermediários de nitrorredução ao DNA promove questionamentos sobre o caráter mutagênico e neoplásico dos nitrocompostos. Neste sentido, alguns pesquisadores têm demonstrado que alguns nitrocompostos causam anomalias cromossômicas em mamíferos, o que sugere a ocorrência de efeito genotóxico e mutagênico. ${ }^{78}$ Em estudos de relações quantitativas entre estrutura química e atividade mutagênica dos nitrocompostos demonstrou-se a existência de correlação entre valores altos de afinidade eletrônica, juntamente com o número de núcleos heterocíclicos presentes na estrutura dos nitrocompostos, e sua atividade mutagênica. ${ }^{79-81}$ Adicionalmente, Fu, em 1990, sugeriu que a introdução de um ou mais grupos nitro em compostos policíclicos pode aumentar consideravelmente a possibilidade do efeito mutagênico e carcinogênico destes compostos. ${ }^{82}$ Do mesmo modo, Xu e colaboradores, em 2002, indicaram que a toxicidade desta classe de compostos é dependente da proporção e também da posição de grupos nitro ligados a anéis aromáticos ${ }^{83}$ Por outro lado, em trabalhos desenvolvidos especificamente com derivados nitrofurânicos ${ }^{79}$ e o metronidazol, ${ }^{84}$ foi sugerido que a mutagenicidade ocorre através da reação de intermediários nucleofílicos, formados a partir da ruptura do anel furânico ou imidazólico, com o DNA celular. Este mecanismo pode ser, juntamente com o metabolismo do grupo nitro, responsável pela ativação de oncogenes ou pela inativação dos genes supressores de tumores, permitindo, assim, o desenvolvimento de câncer. ${ }^{79}$

Em alguns casos, a toxicidade resultante da atividade de alguns nitrocompostos em mamíferos torna-se questionável, uma vez que a mesma não é reproduzida a partir de resultados positivos obtidos em procedimentos experimentais in vitro. Neste sentido, a atividade mutagênica de alguns nitrofurânicos e nitroimidazóis foi avaliada e demonstrada através do Teste de Ames realizado em Salmonella typhimurium; ${ }^{85}$ estes testes, no entanto, não apresentaram mutagenicidade em células de mamíferos. ${ }^{86}$ Já para o efeito tóxico e mutagênico dos nitrocompostos em bactérias estima-se que este pode ser devido a danos causados ao DNA, ${ }^{87}$ seja pelos adutos formados com derivados nitrosos ou por meio da interação das bases púricas ou pirimídicas com radicais livres provenientes do processo de redução. ${ }^{88}$

Blumenstiel e colaboradores, em 1999, utilizando diversos derivados nitrofurânicos com atividade frente ao Trypanosoma cruzi comprovaram que alguns compostos como a nifuroxazida e o nifuprazine não apresentam efeitos tóxicos às células de mamíferos quando em concentrações menores que $10 \mu \mathrm{M} .{ }^{30}$ Adicionalmente, em estudo realizado com dois derivados nitrofurânicos distintos, a nifuroxazida e a nitrofurantoína, foi demonstrado que a ação mutagênica é dependente da estrutura química e da concentração do nitrocomposto em determinado órgão ou tecido. ${ }^{89}$ Considerando o mesmo raciocínio, em estudo de citotoxidade realizado por Rossa e colaboradores, em 2003, foi sugerido que o nitrofurânico analisado, o quinifuril, em comparação a outro nitrocomposto, a nitracrina, já disponível na terapêutica, apresentou alta toxicidade in vitro em células leucêmicas de rato e baixa toxicidade em células de animais normais. ${ }^{66} \mathrm{~A}$ partir do exposto, torna-se plausível supor que a provável ação mutagênica, assim como a toxicidade dos nitrocompostos é dependente de fatores como a estrutura química, ${ }^{71,89-94}$ tempo de exposição e dose utilizada, o que demonstra a possibilidade, sob condições controladas, do emprego terapêutico de alguns nitrocompostos.

\section{CONSIDERAÇÕES FINAIS}

Os nitrocompostos constituem atualmente uma importante classe terapêutica devido ao amplo espectro de atividade. Com relação aos mecanismos de ação destes compostos, observa-se que a redução do grupo nitro in vivo é fundamental para o estabelecimento da atividade 
biológica da maioria dos nitrocompostos. Os radicais livres formados no processo de biorredução têm vida curta, mas supõe-se que esta seja suficientemente longa para migrar do local de produção para os vários alvos biológicos ou mesmo que sejam formados junto ao local de ação, podendo reagir com o DNA, enzimas ou com membranas biológicas.

O mecanismo de ação é sabidamente dependente da estrutura destes compostos, constituindo-se, desta forma, em área promissora para estudos e aplicações terapêuticas futuras. A possibilidade de planejamento da ocorrência de biorredução do grupo nitro em meio ou alvo biológico pré-determinado, considerandos fatores como potencial de redução, $\mathrm{pH}$ e presença de oxigênio no meio, ainda é pouco explorada, mas representa um grande nicho de possibilidades para fins farmacológicos. Neste sentido, o emprego de ferramentas de modulação da estrutura dos nitrocompostos, como o bioisosterismo entre outras, que possibilitam o planejamento de moléculas com melhor perfil farmacológico se apresenta extremamente promissor.

\section{REFERÊNCIAS}

1. Katzung, B. G.; Farmacologia Básica e Clínica, 8 a ed., Guanabara Koogan: Rio de Janeiro, 2001, cap. 52.

2. World Health Organization; www.who.int/tdr/grants/workplans/pdf/drug. pdf, acessada em Junho 2008..

3. Sartori, A. M. C.; Ibrahim, K. Y.; Westphalen, E. V. N.; Braz, L. M. A.; Oliveira, O. C., Jr.; Gakiyat, E.; Lopes, M. H.; Shikanai-Yasuda, M. A; Ann.Trop. Med. Paras. 2007, 101, 31; Coura, J. R.; Castro, S. L.; Mem. Inst. Oswaldo Cruz 2002, 97, 3.

4. Silveira, G. P.; Nome, F.; Gesser, J. C.; Sá, M. M.; Terenzi, H.; Quim. Nova 2006, 29, 844; Van Bambeke, F. V.; Michot, J.-M. J.; Van Eldere, J. V.; Tulkens, P. M.; Clin. Microb. Infec. 2005, 11, 2; Woodford, N.; Clin. Microb. Infec. 2005, 11, 2; Gelb, M. H.; Hol, W. G. J.; Science 2002, 297, 343; Aucken, H. M.; Ganner, M.; Murchan, S.; Cookson, B. D.; Johnson, A. P.; J. Antimicrob. Chemother. 2002, 50, 171; Urbina, J. A.; Cur. Opin. Infec. Disease 2001, 14, 733; Geisel, R.; Schimitz, F. J.; Thomas, L.; Berns, G.; Zetsche, O.; Urlich, B.; Fluit, A. C.; Labischinsky, H.; Witte, W.; J. Antimicrob. Chemoter. 1999, 43, 846; Murta, S. M. F.; Gazzinelli, R. T.; Brener, Z.; Mol. Biochem. Parasitol. 1998, 93, 203; Croft, S. L.; Parasitology 1997, 114, S3.

5. Rauth, A. M.; Melo, T.; Misra, V.; Int. J. Rad. Oncol. Biol. Phys. 1998, $42,755$.

6. Horrocks, S. M.; Jung, Y. S.; Huwe, J. K.; Harvey, R. B.; Ricke, S. C.; Carstens, G. E.; Callaway, T. R.; Anderson, R. C.; Ramlachan, N.; Nisbet, D. J., J. Food Sci., 2007, 72, M50; Raether, W.; Hanel, H.; Parasitol. Res. 2003, 90, S19.

7. Remers, W. A.; Bears, S.; Burger's Medicinal Chemistry and Drug Discovery, $5^{\text {th }}$ ed., Wiley Interscience: New York, 1997, vol. 4, cap. 4, p. 271-272.

8. Dodd, M. C.; Stillman, W. B.; J. Pharmacol. Exp. Ther. 1944, 82, 11.

9. Korolkovas, A.; França, F. F. A. C.; Dicionário Terapêutico Guanabara 2007/2008, 14 ed., Guanabara Koogan: Rio de Janeiro, 2007, 10.2310.27, 19.11-19.12.

10. Yan, X.-F.; Xiao, H.-M.; Gong, S.-D.; Ju, S.-H.; Chemosphere 2005, 59, 467.

11. Korolkovas, A.; Burckhalter, J. H.; Química Farmacêutica, Guanabara Koogan: Rio de Janeiro, 1988, p. 65, 542, 544-545.

12. Lemke, T. L.; Willians, D. A., FOYE'S Principles of Medicinal Chemistry, $6^{\text {th }}$ ed., Lippincott Williams \& Wilkins: Baltimore, 2008.

13. Herlich, P.; Scweigel, M.; Proc. Natl. Acad. Sci. U.S.A. 1976, 73, 3386.

14. Tocher, J. H.; Gen. Pharmac. 1997, 28, 485.

15. Rang, H. P.; Ritter, J. M.; Dale, M. M.; Moore, P. K., eds.; Farmacologia, $5^{a}$ ed., Elsevier: Rio de Janeiro, 2004; Barreiro, E. J.; Fraga, C. A. M.;
Química Medicinal, $1^{\mathrm{a}}$ ed., Artmed: Porto Alegre, 2001; Lana, M.; Taffuri, W. L., Em Parasitologia Humana; Neves, D. P., ed.; 10ª ed., Ed. Atheneu: São Paulo, 2000, p. 73-96; Hardman, J. G.; Limbird, L. E.; Gilman, A. G.; Goomann \& Gilman - The Pharmacological Basis of therapeutics, $9^{\text {th }}$ ed., McGraw-Hill: New York, 1996.

16. Viodé, C.; Bettache, N.; Cenas, N.; Krauth-Siegel, R. L.; Chauviére, G.; Bakalara, N.; Périé, J.; Biochem. Pharmac. 1998, 57, 549.

17. Maya, J. D.; Cassels, B. K.; Iturriaga-Vásquez, P.; Ferreira, J.; Faúndez, M.; Galanti, N.; Ferreira, A.; Morello, A., Comp. Biochem. Phys. Part A 2007, 146, 601

18. Vanelle, P.; Ghezali, S.; Maldonado, J.; Crozet, M. P.; Delmas, F.; Gasquet, M.; Timon-David, P.; Eur. J. Med. Chem. 1994, 29, 41.

19. Cerecetto, H.; Di Maio, R.; Ibarruri, G.; Seone, G.; Denicola, A.; Peluffo, G.; Quijano, C.; Paulino, M.; Il Farmaco 1998, 53, 89.

20. Bharti, N.; Husain, K.; Garza, M. T. G.; Cruz-Vega, D. E.; Castro-Garza, J.; Mata-Cardenas, B. D.; Naqvi, F.; Azam, A.; Bioorg. Med. Chem. Lett. 2002, 12, 3475 .

21. Masunari, A.; Tavares, L. C.; Bioorg. Med. Chem. 2007, 15, 4229; Masunari, A.; Tavares, L. C., Rev. Bras. Cien. Farm. 2006, 42, 463; Masunari, A.; Tavares, L. C.; Resumos do XVII th International Symposium on Medicinal Chemistry, Barcelona, Spain, 2002.

22. Rando, D. G.; Sato, D. N.; Siqueira, L.; Malvezzi, A.; Leite, C. Q. F.; Amaral, A. T.; Ferreira, E. I.; Tavares, L. C.; Bioorg. Med. Chem. 2002, 10, 557.

23. Behrouzi-Fardmoghadam, M.; Poorrajab, F.; Ardestani, S. K.; Emami, S.; Shafiee, A.; Foroumadi, A.; Bioorg. Med. Chem. 2008, 16, 4509; Stewart, M. L.; Bueno, G. J.; Baliani, A.; Klenke, B.; Brun, R.; Brock, J. M.; Gilbert, I. H.; Barrett, M. P.; Antimic. Agents Chemother. 2004, $48,1733$.

24. Foroumadi, A.; Pournourmohammadi, S.; Soltani, F.; Asgharian-Rezaee, M.; Dabiri, S.; Kharazmi, A.; Shafiee, A.; Bioorg. Med. Chem. Lett. 2005, 15, 1983

25. Cerecetto, H.; Di Maio, R.; Gonzáles, M.; Risso, M.; Sagrera, G.; Seone, G.; Denicola, A.; Peluffo, G.; Quijano, C.; Stoppani, A. O. M.; Paulino, M.; Olea-Azar, C.; Basombrio, M.A.; Eur. J. Med. Chem. 2000, 35, 343.

26. Martinez-Merino, V.; Cerecetto, H.; Bioorg. Med. Chem. 2001, 9, 1025.

27. Maya, J. D.; Bollo, S.; Nunes-Vergara, L. J.; Squella, J. A.; Repetto, Y.; Morello, A.; Périe, J.; Chauviére, G.; Biochem. Pharmacol. 2003, 65, 999.

28. Vega-Teijido, V.; Caracelli, I.; Zukerman-Schpector, J.; J. Mol. Graph. Model. 2006, 24, 349.

29. Kinnamon, K. E.; Poon, B. T.; Hanson, W. L.; Waits, V. B.; Exp. Parasitology 1998, 89, 251.

30. Blumesntiel, K.; Schöneck, R.; Yardley, V.; Croft, S. L.; Krauft-Siegel, R. L.; Biochem. Pharmacol. 1999, 58, 1791.

31. Gerpe, A.; Odreman-Nuñez, I.; Draper, P.; Boiani, L.; Urbina, J. A.; González, M.; Cerecetto, H.; Bioorg. Med. Chem. 2008, 16, 259; Rigol, C.; Olea-Azar, C.; Mendizábal, F.; Briones, R.; Cerecetto, H.; González, M.; J. Mol. Struc. (Theochem) 2006, 770, 125; Paulino, M.; Iribarne, F.; Hansz, M.; Veja, M.; Seone, G.; Cerecetto, H.; Di Maio, R.; Caracelli, I.; Zukerman-Schpector, J.; Olea, C.; Stoppani, A. O. M.; Berriman, M.; Fairlamb, A. H.; Tapia, O.; J. Mol. Struct. (Theo Chem) 2002, 584, 95.

32. Chung, M. C.; Güido, R. V. C.; Martinelli, T. F.; Gonçalves, M. F.; Polli, M. C.; Botelho, K. C. A.; Varanda, E. A.; Colli, W.; Miranda, T. M.; Ferreira, E. I.; Bioorg. Med. Chem. 2003, 11, 4779.

33. Aguirre, G.; Cabrera, E.; Cerecetto, H.; Di Maio, R.; Gonzáles, M.; Seone, G.; Duffaut, A.; Denicola, A.; Gil, M. J.; Martinez-Merino, V.; Eur. J. Med. Chem. 2004, 39, 421.

34. Soriano-Correia, C.; Raya, A.; Esquivel, R. O.; Int. J. Quantum Chem. 2008, 108, 1369; Pozas, R.; Carballo, J.; Castro, C.; Rubio, J.; Bioorg. Med. Chem. Lett. 2005, 15, 1417.

35. Aguirre, G.; Boiani, M.; Cabrera, E.; Cerecetto, H.; Di Maio, R.; Gonzáles, M.; Denicola, A.; Sant'Anna, C. M. R.; Barreiro, E. J.; Eur. J. Med. Chem. 2006, 41, 457. 
36. Otero, L.; Vieites, M.; Boiani, L.; Denicola, A.; Rigol, C.; Opazo, L.; Olea-Azar, C.; Maya, J. D.; Morello, A.; Krauth-Siegel, R. L.; Piro, O. E.; Castellano, E.; Gonzalez, M.; Gambino, D.; Cerecetto, H.; J. Med. Chem. 2006, 49, 3322.

37. Pires, J. R.; Saito, C.; Gomes, S. L.; Giesbrecht, A. M.; Amaral, A. T.; J. Med. Chem. 2001, 44, 3673.

38. Tavares, L. C.; Penna, T. V. C.; Amaral, A. T.; Boll. Chim. Farm. 1997, 136, 244.

39. Tavares, L. C.; Chisté, J. J.; Santos, M. G. B.; Penna, T. C. V.; Boll. Chim. Farm. 1999, 8, 432

40. Srivastava, B. K.; Jain, M. R.; Solanki, M.; Soni, R.; Valani, D.; Gupta, S.; Mishra, B.; Takale, V.; Kapadnis, P.; Patel, H.; Pandya, P.; Patel, J. Z.; Patel, P. R.; Eur. J. Med. Chem. 2008 43, 683; Costello, C.; Karpanen, T.; Lambert, P. A.; Mistry, P.; Parker, K. J.; Rathbone, D. L.; Ren, J.; Wheeldon, L.; Worthington, T.; Bioorg. Med. Chem. Lett. 2008 18, 1708; Rollas, S.; Gulerman, N.; Erdeniz, H.; Il Farmaco 2002, 57, 171.

41. De La Fuente, R.; Sonawane, N. D.; Arumainayagam, D.; Verkman, A. S.; Brit. J. Pharm. 2006, 149, 551; Monastérios, M.; Escorche, M.; Averdano, M.; J. Mol. Struct. 2005, 748, 49.

42. Tangallapally, R. P.; Yendapally, R.; Daniels, A. J.; Lee, R. E. B.; Lee, R. E.; Curr. Top. Med. Chem. 2007, 7, 509.

43. Sharma, S.; Athar, F.; Maurya, M. R.; Naqyi, F.; Azam, A.; Eur. J. Med. Chem. 2005, 40, 557.

44. Rozenski, J.; De Raunter, C. J.; Verplanken, H.; Quant. Struct.-Act Relat. 1995, 14, 134.

45. Stover, C. K.; Warrener, P.; VanDevanter, S. D. R.; Arain, T. M.; Langhorne, M. H.; Anderson, S. W.; Towell, J. A.; Yuan, Y.; McMurray, D. N.; Kreiswirth, B. N.; Barryl, C. E.; Baker, W. R.; Nature 2000, 405, 962.

46. Foroumadi, A.; Kargar, Z.; Sakhteman, A.; Sharifzadeh, Z.; Feyzmohammadi, R.; Kazemi, M.; Shafiee, A.; Bioorg. Med. Chem. Lett. 2006, 16, 1164.

47. Henderson, G. B.; Urlich, P.; Fairlamb, A. H.; Rosemberg, I.; Pereira, M.; Sela, M.; Cerami, A.; Proc. Nat. Acad. Sci. U.S.A. 1988, 85, 5374.

48. Rosseli, F. P.; Albuquerque, C. N.; da Silva, A. B. F.; Int. J. Quant. Chem. 2005, 103, 738 .

49. Carvalho, A. S.; Gibaldi, D.; Pinto, A. C.; Bozza, M.; Boechat, N.; Lett. Drug Des. Disc. 2006, 3, 98.

50. Mahfouz, N. M.; Aboul-Fadl, T.; Diab, A. K.; Eur. J. Med. Chem. 1998 33,675 .

51. Castelli, M.; Malagoli, M.; Ruberto, A. I.; Baggio, A.; Casolari, C.; Cermelli, C.; Bossa, M. R.; Rossi, T.; Paolucci, F.; Roffia, S.; J. Antimicrob. Chemother. 1997, 40, 19.

52. Edwards, D. I.; Biochem. Pharmacol. 1986, 35, 53.

53. Kappus, H.; Biochem. Pharmacol. 1986, 35, 1.

54. Nünez-Vergara, L. J.; Salazar, R.; Navarrette-Encina, P. A.; Camargo, C.; Yanez, C.; Squella, J. A.; J. Electrochem. Soc. 2007, 154, F25; Julião, M. S. S.; Ferreira, E. I.; Ferreira, N. G.; Serrano, S. H. P.; Electroc. Acta 2006, 51, 5080; Julião, M. S. S.; Almeida, E. C.; La-Scalea, M. A.; Ferreira, N. G.; Compton, R.; Serrano, S. H. P.; Electroanalysis 2005, 17, 269; Squella, J. A.; Bollo, S.; Nünes-Vergara, L. J.; Curr. Org. Chem. 2005, 9, 565; Mandal, P. C.; J. Electroanal. Chem. 2004, 570, 55; Bollo, S.; Nunes-Vergara, L. J.; Martinez, C.; Chauviere, G.; Périe, J.; Squella, J. A.; Electroanalysis 2003, 15, 19; La-Scalea, M. A.; Serrano, S. H. P. Gutz, G. R.; J. Braz. Chem. Soc. 1999, 10, 127; La-Scalea, M. A.; Rev. Farm. Bioquim. Univ. São Paulo 1999, 10, 127; Squella, J. A.; Letelier, M. E.; Lindermeyer, L.; Nünes-Vergara, L. J.; Chem. Biol. Interac. 1996 99, 227; Karakus, C.; Zuman, P.; J. Electroanal. Chem. 1995, 396, 499; Monteagudo, J. C. G.; Fonseca, J. M. L.; Crespo, M. A.; Pharmazie 1992, 47, 98; Morales, A.; Richter, P.; Toral, M. I.; Analyst 1987, 112, 965.

55. Edwards, D. I.; J. Antimicrob. Chemother. 1993, 31, 09.

56. Roldán, M. D.; Pérez-Reinaldo, E.; Castillo, F.; Moreno-Vivián, C.; FEMS Microbiol. Rev. 2008, 32, 474; Kedderis, G. L.; Miwa, G. T.; Drugs Metabolism Reviews 1988, 19, 33.
57. Krauth-Siegel, R. L.; Inhoff, O.; Parasitol. Res. 2003, 90, S77; KrauthSiegel, R. L.; Schöneck, R.; FASEB J. 1995, 9, 1138; Jockers-Scherübl, M. C.; Schirmer, R. H.; Krauth-Siegel, R. L.; Eur. J. Biochem. 1989, 180, 267; Krauth-Siegel, R. L.; Enders, B.; Henderson, B. G.; Fairlamb, A. H.; Schirmer, R. H.; Eur. J. Biochem. 1987, 164, 123.

58. Edwards, D. I. Comprehensive medicinal chemistry; Hansch, C.; Sammes, P. G., eds.; Pergamon Press: Oxford, 1990, vol. 2, p. 725-751.

59. Gringauz, A.; Introduction to Medicinal Chemistry. How Drug Act and Why, $1^{\text {st }}$ ed., Wiley-VCH: New York, 1997.

60. Maya, J. D.; Repetto, Y.; Agosin, M.; Ojeda, J. M.; Tellez, R.; Gaule, C.; Morello, A.; Molec. Biochem. Parasitology. 1997, 86, 101.

61. McOsker, C. C.; Fitzpatrick, P. M.; J. Antimicrob. Chemother. 1994, 33, 23.

62. Declerck, P. J.; De Ranter, C. J.; Biochem. Pharmacol. 1986, 35, 59.

63. Al-Masoudi, N. A.; Al-Soud, Y. A.; Kalogerakis, A.; Pannecouque, C.; De Clercq, E.; Chem. Biodiv. 2006, 3, 515.

64. Cenas, N.; Prast, S.; Nivinskas, H.; Saurlauskas, J.; Arnér, E. S. J.; J. Biol. Chem. 2006, 281, 5593.

65. Krauze, W.; Jordan, A.; Scholz, R.; Jimenez, J. L. M.; Anticancer Res. 2005, 25, 2145.

66. Rossa, M. M.; Rocha-e-Silva, T. A. A.; Terruggi, C. H. B.; Tedesco, A. C.; Selistre-de-Araujo, H. S.; Borissevich, I. E.; Degterev, I. A.; Pharmacol. Res. 2003, 48, 369.

67. Khlebnikov, A.; Schepetkin, I.; Kwon, B. S.; Cancer Biother. Radiopharm. 2002, 17, 193.

68. Zhu, W.; Dai, M.; Xu, Y.; Qian, X.; Bioorg. Med. Chem. 2008, 16, 3255; Santos, L.; Cornago, M. P.; Izquierdo, M. C.; Lopez-Zumel, M. C.; Smeyers, Y. T.; Quant. Struct.-Act. Relat. 1989, 8, 214.

69. Zieba-Mizgala, A.; Pusko, A.; Regiec, A.; Kuduk-Jaworska, J.; Biolectrochem. 2005, 65, 113 .

70. Abreu, F. C.; Ferraz, P. A. L.; Goulart, M. O. F.; J. Braz. Chem. Soc. 2002, 13, 19.

71. Chandor, A.; Dijols, S.; Ramassamy, B.; Frapart, Y.; Mansuy, D.; Stuehr, D.; Helsby, N.; Boucher, J. L; Chem. Res. Toxicol. 2008, 21, 836; Rajski, S. R.; Willians, R. M.; Chem. Rev. 1998, 98, 2723.

72. Castro, J. A.; de Mecca, M. M.; Bartel, L. C.; Human Exp. Toxicol. 2006, 25, 471; Jawetz, E.; Melnick, J. L.; Adelberg, E. A.; Brooks, G. F.; Butel, J. S.; Ornston, L. N.; Microbiologia Médica, $18^{\mathrm{a}}$ ed.; Guanabara Koogan: Rio de Janeiro, 1991, cap. 11, 147.

73. Bartel, L. C.; de Mecca, M. M.; Fanelli, S. L.; de Castro, C. R.; Diaz, E. G.; Castro, J. A.; Human Exp. Toxicol. 2007, 26, 781.

74. Wermuth, C. G., ed.; The Practice of Medicinal Chemistry, $1^{\text {st }}$ ed., Academic Press: San Diego, 2000.

75. Chauviere, G.; Bouteille, B.; Enanga, B.; de Albuquerque, C.; Croft,, S L.; Dumas, M.; Perie, J.; J. Med. Chem. 2003, 46, 427.

76. Poli, P.; Mello, M. A.; Buschini, A.; Mortara, R. A.; Albuquerque, C. N.; Silva, S.; Rossi, C.; Zucchi, T. M. A. D.; Biochem. Pharmacol. 2002, 64, 1617.

77. Carvalho, S. A.; da Silva, E. F.; Santa-Rita, R. M.; de Castro, S. L.; Fraga, C. A. M.; Bioorg. Med. Chem. Lett. 2004, 14, 5967.

78. Ahmed, H. H.; El-Aziem, S. H. A.; Abdel-Wahhab, M. A.; Toxicology 2008, 243, 31; Fucic, A.; Markovic, D.; Ferencic, Z.; Mildner, B.; Jazbec, A. M.; Spoljar, J. B.; Environ. Mol. Mutagen 2005, 46, 59; Slapsyte, G.; Jankauskiene, A.; Mierauskiene, J.; Lazutka, J. R.; Mutagenesis 2002, 17, 31 .

79. Compadre, R. L.; Byrd, C.; Compadre, C. M. Em Comparative QSAR; Devillers, J., ed.; $1^{\text {st }}$ ed., Taylor \& Francis: Washington, 1998, cap. 3, p. 111-135.

80. Debnath, A. K.; Hansch, C.; Kim, K. H.; Martin, Y. C.; J. Med. Chem. 1993, 36, 1007

81. Debnath, A. K.; Compadre, R. L. L.; Debnath, G.; Shusteman, A. J.; Hansch, C.; J. Med. Chem. 1991, 34, 786.

82. Fu, P. P.; Drugs Metabolism Reviews 1990, 22, 209. 
83. Xu, M.; Zhang, A.; Han, S.; Wang, L.; Chemosphere 2002, 48, 707.

84. Goldman, P.; Koch, R. L.; Yeung, T. C.; Chrystal, E. J. T.; Beaulieu, B. B.; McLaferty, M. A.; Sudlow, G.; Biochem. Pharmacol. 1986, 35, 43.

85. Ferreira, R. C. C.; Ferreira, L. C. S.; Mem. Inst. Oswaldo Cruz 1986, 81, 49.

86. Dayan, J.; Deguingand, C.; Truzman, C.; Mutat. Res. 1985, 157, 1.

87. Chadfield, M. S.; Hinton, M. H.; J. App. Microb. 2004, 96, 1002.

88. Rickert, D. E.; Drugs Metabolism Reviews 1987, 18, 23.

89. Hofnung, M.; Quillardet, P.; Michel, V.; Touati, E.; Res. Microb. 2002, $153,427$.

90. Morales, A. H.; Pérez, M. A. C.; Combes, R. D.; Gonzáles, M. P.; Toxicology 2006, 220, 51.

91. Mollet, R.; Maes, L.; Landry, V.; Sergheraert, C.; Davioud-Charvet, E.; Bioorg. Med. Chem. Lett. 2002, 12, 3601.

92. Helguera, A. M.; Cordeiro, M. N. D. S.; Pérez, M. A. C.; Combes, R.
D.; González, M. P.; Bioorg. Med. Chem. 2008, 16, 3395; Quillardet, P.; Arrault, X.; Michel, V.; Touati, E.; Mutagenesis 2006, 21, 305; Salamanca-Pinzón, S. G.; Camacho-Carranza, R.; Hernández-Ojeda, S. L.; Espinosa-Aguirre, J. J.; Mutagenesis 2006, 21, 369.

93. Landvik, N. E.; Gorria, M.; Arlt, V. M.; Asare, N.; Solhaug, A.; LagadicGossmann, D.; Holme, J. A.; Toxicology 2007, 231, 159.

94. Nair, P. C.; Sobhia, E.; J. Mol. Graph. Model. 2008, 26, 916; Mudry, M. D.; Palermo, A. M.; Merani, M. C.; Carballo, M. A.; Reprod. Toxicol. 2007, 23, 246; Buschini, A.; Giordani, F.; Albuquerque; C. N.; Pellacani, C.; Pelosi, G.; Rossi, C.; Zucchi, T. M.; Poli, P.; Biochem. Pharmacol. 2007, 73, 1537; Klein, M.; Erdinger, L.; Boche, G.; Mutat. Res. 2000, 467, 69; Debnath, A. K.; Compadre, R. L. L.; Shusterman, A. J.; Hansch, C.; Environ. Mol. Mutagen. 1992, 19, 53.

95. Paula, F. R.; Tese de Doutorado, Universidade de São Paulo, Brasil, 2007. 